Preface

\title{
Pediatric Plastic Surgical Procedures
}

William C. Pederson, MD ${ }^{1}$ Larry H. Hollier, Jr., MD, FACS ${ }^{1}$

${ }^{1}$ Division of Plastic Surgery, Baylor College of Medicine, Houston, Texas

Semin Plast Surg 2016;30:153-154.

It is now generally well accepted that pediatric surgical treatment is quite distinct from surgical treatment in the adult population. Children are not simply "little adults." The psychological and physiological aspects of the care of children are often more challenging than those of adults. We also face a very broad range of plastic surgical conditions in children that are simply not routinely seen in adults. This issue endeavors to bring some of these conditions and unique considerations into focus.

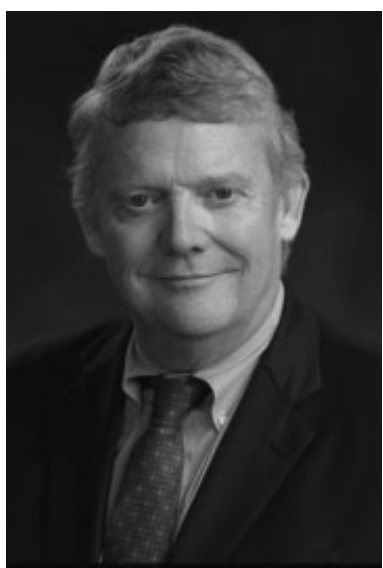

Address for correspondence Larry H. Hollier, MD, FACS, Division of Plastic Surgery, Baylor College of Medicine, 6701 Fannin Street, Suite 610.00, Houston, TX 77030 (e-mail: larryh@bcm.edu).
Issue Theme Pediatric Plastic Surgical Procedures;

Guest Editors, William C. Pederson, MD, and Larry $\mathrm{H}$. Hollier, Jr., MD, FACS
Copyright $\odot 2016$ by Thieme Medical Publishers, Inc., 333 Seventh Avenue, New York, NY 10001, USA.

Tel: +1(212) 584-4662.
DOI http://dx.doi.org/ 10.1055/s-0036-1593480. ISSN 1535-2188. 